\title{
O QUE REVELA A ESCRITA DE PROFESSORAS SOBRE O GÊNERO DISSERTAÇÃO DE MESTRADO?
}

What does teachers writing reveal about the professional master's thesis genre?

¿Qué revela la escritura de profesoras sobre el género disertación del máster profesional?

\section{Wagner Rodrigues Silva ${ }^{* 1}$, Roseane Ferreira ${ }^{1}$, Nayra Aires ${ }^{1}$,}

${ }^{1}$ Grupo de Pesquisa Práticas de Linguagens - PLES, Docente da Licenciatura em Pedagogia, Universidade Federal do Tocantins, Palmas, Toca Brasil.

*Correspondência: Licenciatura em Pedagogia, Quadra ARNO 14, Av. NS 15, Bloco Bala II, Palmas, Tocantins, Brasil.CEP:77.010-090.e-mail wagnersilva@uft.edu.br.

\section{RESUMO}

Este artigo focaliza o processo de educação científica de professoras de Língua Portuguesa (LP), matriculadas num mestrado profissional para educadores, oferecido como política pública oficial de formação no Brasil. A investigação do referido processo foi realizada a partir da análise de dissertações de mestrado, apresentadas como trabalhos de conclusão final (TCF). A investigação focalizou mais diretamente os objetos de pesquisa e as autorrepresentações presentes nos TCF. Utilizamos as abordagens investigativas qualitativa e quantitativa. A pesquisa se insere no campo da Linguística Aplicada (LA) e foi informada principalmente por estudos do letramento e da educação científica. Fizemos uso da Linguística Sistêmico-Funcional (LSF) para a realização da microanálise dos documentos investigados. O exame da estrutura esquemática das dissertações selecionadas também contribuiu para a investigação. Os resultados mostraram o desenvolvimento da educação científica das professoras de LP, a qual foi influenciada por práticas científicas da tradição acadêmica. Um exemplo dessa influência corresponde a supervalorização dos pressupostos teóricos utilizados em detrimento da exploração das experiências da prática profissional das professoras na escola básica.

Palavras-chave: Educação científica; Letramentos; Gênero.

\begin{abstract}
This article focuses on the scientific education process of Portuguese Language (PL) teachers, enrolled in a professional master's degree program for educators, offered as an official educational public policy in Brazil. The investigation of this process was carried out from the analysis of masters' thesis, presented as final conclusion works $(F C W)$. The investigation focused more directly on the research objects and self-representations present in the FCW. We used qualitative and quantitative investigative approaches. The research is situated in the field of Applied Linguistics $(A L)$ and was mainly informed by studies of literacy and scientific education. We used the Systemic Functional Linguistics (SFL) to carry out the microanalysis of the investigated documents. Examination of the schematic structure of the selected thesis also contributed to the investigation. The results showed the development of PL teachers' scientific education, which was influenced by scientific practices from the academic tradition. An example of this influence corresponds to the overvaluation of the theoretical assumptions used to the detriment of the exploration of the experiences of teachers' professional practice in elementary school.
\end{abstract}

Keywords: Scientific Education; Literacies; Genre. 


\section{RESUMEN}

Este artículo se centra en el proceso de formación científica de los profesores de Lengua Portuguesa (LP), matriculados en un programa profesional de máster para educadores, ofrecida como política pública oficial para la formación en Brasil. La investigación de este proceso se realizó a partir del análisis de las disertaciones de máster, presentadas como trabajos de conclusión final (TCF). La investigación se centró más directamente en los objetos de investigación y en las autorrepresentaciones presentes en el TCF. Utilizamos enfoques de investigación cualitativos y cuantitativos. La investigación se enmarca en el campo de la Lingüística Aplicada $(A L)$ y se basó principalmente en estudios de literacia y educación científica. Utilizamos la Lingüística Sistémica Funcional (LSF) para realizar el microanálisis de los documentos investigados. El examen de la estructura esquemática de las disertaciones seleccionadas también contribuyó a la investigación. Los resultados mostraron el desarrollo de la formación científica de los docentes de LP, que estuvo influenciada por prácticas científicas de la tradición académica. Un ejemplo de esta influencia corresponde a la sobrevaloración de los supuestos teóricos utilizados en detrimento de la exploración de las experiencias de la práctica profesional de los docentes en las escuelas primarias.

Descriptores: Educación científica; Literacidad; Género.

\section{INTRODUÇÃO}

O Mestrado Profissional em Letras (ProfLetras) é um curso em rede de âmbito nacional, ofertado pelo Governo Federal para professoras da Educação Básica, com Licenciatura em Língua Portuguesa, e que estejam exercendo o magistério em alguma unidade escolar da rede pública ${ }^{1}$. Para ter acesso ao mestrado profissional (MP), é realizado anualmente um Exame Nacional de Acesso, nas Instituições de Ensino Superior (IES) associadas ao programa. Este exame consiste em uma prova para avaliar conhecimentos linguísticos com ênfase em habilidades de leitura e de escrita das candidatas. Após aprovação, podem se matricular no ProfLetras para realizar o mestrado com duração idealizada de 24 meses (cf. PROFLETRAS REGIMENTO anexo à Res no 043/2012).

As unidades do ProfLetras estão distribuídas nas cinco regiões geográficas brasileiras. Para este estudo, selecionamos algumas dissertações de mestrado produzidas em unidades acadêmicas da Bahia e Pernambuco. Trabalhos finais produzidos nos Estados do Pará e Tocantins foram focalizados em outras pesquisas (SILVA e AIRES, 2020; SILVA e FERREIRA, 2020). Para a obtenção da titulação de

\footnotetext{
${ }^{1}$ Optamos por utilizar a forma professora para nos referir ao corpo discente do ProfLetras, pois é composto predominantemente por mulheres. As dissertações de
}

Mestra em Letras, é necessário que as professoras produzam um Trabalho de Conclusão Final (TCF), configurado como Dissertação de Mestrado (DM). Tais trabalhos foram concebidos como objetos de investigação no projeto de pesquisa Letramento Científico do Professor no Mestrado Profissional em Letras (CNPq 305094/2016-5), desenvolvido no grupo de pesquisa Práticas de Linguagens - PLES (UFT/CNPq). No referido grupo, há pós-graduandos desenvolvendo pesquisa com TCF produzidos em unidades acadêmicas de outros Estados.

Analisamos as dissertações selecionadas para caracterizar o desenvolvimento da educação científica de professoras de educação básica matriculadas no ProfLetras. Respondemos aos seguintes objetivos específicos: (1) caracterizar os objetos de investigação construídos em dissertações de mestrado examinadas, identificando possíveis relações desses objetos com as demandas pedagógicas para aulas de Língua Portuguesa (LP), na escola de ensino básico, também explicitadas nas dissertações; (2) identificar e descrever autorrepresentações produzidas a partir da escrita de dissertações de mestrado no ProfLetras, elaboradas por professoras de educação básica.

metrado investigadas neste artigo foram escritas por mulheres. 
Buscamos compreender o fortalecimento da educação científica de professoras da educação básica, a partir do exame de dissertações por elas produzidas. Assim, pontuamos algumas contribuições desencadeadas pelo referido curso para a educação científica das profissionais do magistério.

Elas permanecem em serviço mesmo cursando o mestrado, pois, dada a natureza profissional do curso, não podem se afastar da sala de aula. Se por um lado a permanência das professoras em sala pode intensificar a sobrecarga de trabalho docente, por outro, pode trazer contribuições, pois as professoras devem fazer pesquisas no próprio local de trabalho e isso faz com que o crescimento profissional e o conhecimento científico advindo das práticas investigativas se tornem mais sustentáveis.

\section{REVISÃO DA LITERATURA CIENTÍFICA}

Esta investigação está inserida no campo indisciplinar da Linguística Aplicada (LA), que objetiva produzir conhecimentos científicos envolvendo atividades mediadas pela linguagem, atreladas a problemas cotidianos, perpassando diferentes camadas sociais, principalmente grupos subalternizados ou menos visibilizados. Neste sentido, autores como Moita Lopes e Fabrício (2019), Pennycook (2001) e Silva (2021) concebem a LA como crítica, pois questiona situações assimétricas e não deixa de lado as subjetividades do pesquisador e das pessoas envolvidas no estudo. Trata-se de "uma abordagem crítica que se proponha a abrir mão de certezas" (MOITA LOPES e FABRÍCIO, 2019, p. 717). Conforme esses últimos autores, a LA Crítica:

\footnotetext{
se baseia na noção de que o conhecimento vem de algum lugar: o/a pesquisador/a e sua subjetividade são fundamentais. Assim, em vez de se pautar por distância crítica, i.e. o apagamento do sujeito que pesquisa, uma LA crítica enfatiza a performance do/a pesquisador/a, entendendo que modos de falar, sentir, sofrer, gozar etc. são inseparáveis do ato de pesquisar. (MOITA LOPES; FABRÍCIO, 2019, p. 713)
}

Examinamos algumas dissertações de mestrado e valorizamos o que as professoras construíram em suas pesquisas interventivas no próprio local de trabalho, conforme registrado nos TCF. Essas pesquisas devem ser motivadas por problemáticas identificadas, requerendo algum encaminhamento ou solução. Há expectativas de que contribuições significativas se originem dos estudos produzidos, uma vez que, ao retornar à universidade, as professoras levam experiências acumuladas, que podem ser compartilhadas e negociadas com formadores e outras professoras da escola básica no espaço universitário.

Nossa intenção é reconhecer o papel da professora como participante efetiva do sistema educativo com base nos saberes utilizados na prática. Compreendemos que é necessário que a referida profissional exerça a função de agente de letramento: viabilize a inserção do aluno em relevantes práticas sociais de letramento conforme interesses e demandas locais (KLEIMAN, 2006). Nesse sentido, o letramento envolve a utilização da leitura e da escrita para a realização de ações significativas, que valorizem a diversidade cultural característica de contextos sociais igualmente diversos.

Para focalizar o trabalho investigativo das professoras, utilizamos como fundamentação teórica as abordagens dos letramentos do professor, científico e acadêmico. Essas abordagens nos auxiliam a observar as práticas de escrita e pesquisa assumidas pelas professoras e evidenciadas nas dissertações selecionadas.

O letramento do professor, por sua vez, compreende as práticas de leitura e escrita utilizadas por professoras no próprio exercício profissional (KLEIMAN, 2014). São professoras que conhecem as demandas dos alunos e organizam a prática pedagógica conforme as necessidades do ofício, assim refletem sobre as próprias práticas profissionais, analisam o trabalho realizado a fim de reconhecer e 
contribuir para a solução de problemas encontrados. Por letramento científico, compreendemos, de acordo com Silva et al (2018, p, 7), o processo que possibilita que as pessoas estejam "aptas a acessar e produzir conhecimentos científicos mediados pela escrita, de modo que possibilite o olhar e a intervenção consciente e crítica no mundo real". Nesse sentido, o letramento científico desperta a sensibilidade diante de demandas por saberes ou práticas científicas. A ciência é apreendida como atividade que pode auxiliar na compreensão e intervenção de/em realidades sociais percebidas pelo indivíduo. Assim, esse conceito permite a consciência sobre o impacto da ciência (ou ausência dela) no cotidiano.

Existem compreensões semelhantes sobre os usos de saberes e práticas científicas identificados por terminologias distintas, a saber: letramento científico e alfabetização científica. Neste estudo, utilizamos tais nomenclaturas para conceitos diferenciados, porém, complementares. A alfabetização científica corresponde ao conhecimento de práticas de pesquisas, ou seja, é a compreensão de percursos ou procedimentos teórico-metodológicos necessários à realização de investigações, a exemplo do discernimento sobre diferentes abordagens do letramento, necessárias à realização deste estudo. Para Silva (2019a, p. 34), a alfabetização científica "se caracteriza pelo metaconhecimento de procedimentos ou práticas necessárias para a realização de investigação científica". Complementando o fenômeno da referida alfabetização, o letramento científico corresponde ao olhar crítico a respeito dos saberes e práticas científicas mediadas pela escrita.

Finalmente, por letramento acadêmico, considerando o enfoque comumente assumido em pesquisas aplicadas brasileiras, compreendemos as práticas de escrita e leitura necessárias para o trânsito dos acadêmicos no espaço universitário, acrescendose aí as valorações construídas em torno dessas práticas. Segundo Lea e Street (2014, p. 3), "letramentos acadêmicos têm relação com a produção de sentido, identidade, poder e autoridade; coloca em primeiro plano a natureza institucional daquilo que conta como conhecimento em qualquer contexto acadêmico específico". Portanto, a escrita apresenta ou evidencia identidades e possíveis relações assimétricas existentes no contexto instrucional. Esse enfoque vai além da ênfase em aspectos das formas textuais, envolve elementos contextuais. Importa-nos ainda realçar que essas diferentes perspectivas dos letramentos se apresentam de forma fluida, relacionadas entre si, podemos representá-los em um triângulo em que as três pontas se conectam uma à outra em um sentido de continuidade.

Figura 1. Abordagens dos Letramentos.

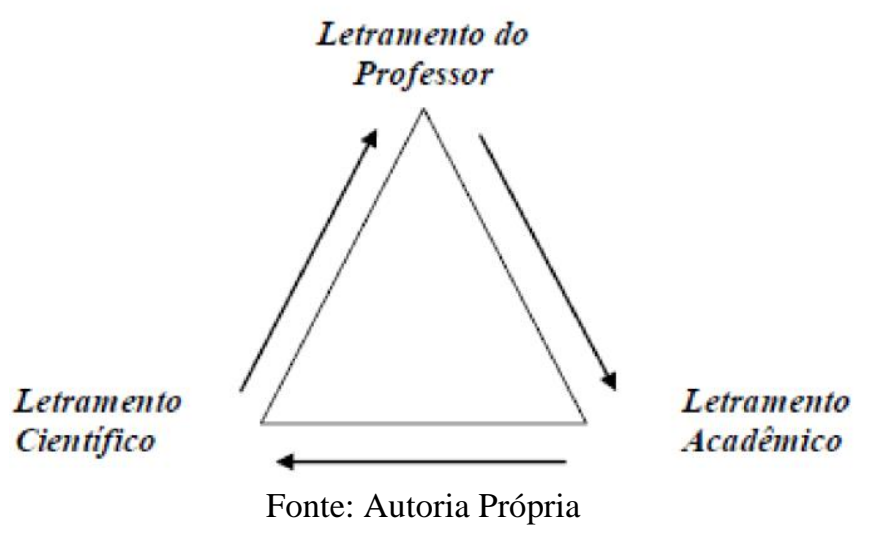

Não há como pensar em educação científica e neutralizar as perspectivas dos estudos dos letramentos. Apesar de distintos, todos os conceitos se relacionam, interferem uns nos outros. Com isso, investigamos a escrita dos TCF produzidos no ProfLetras, na perspectiva da Educação Científica.

\section{PROCEDIMENTOS METODOLÓGICOS}

Esta pesquisa se caracteriza como uma análise documental, o que é justificado pelo objeto de investigação focalizado. Enquanto gênero textual, as dissertações apresentam informações a respeito do processo de formação das professoras. De acordo com 
Gil (2008, p.147), “fontes documentais são capazes de proporcionar ao pesquisador dados em quantidade e qualidade suficiente para evitar a perda de tempo e o constrangimento que caracterizam muitas das pesquisas em que os dados são obtidos diretamente das pessoas”. Não diríamos que as pesquisas com pessoas proporcionam perda de tempo, conforme afirma Gil (2008), mas demandam um investimento significativo de tempo e, dependendo dos propósitos investigativos, torna-se imprescindível o envolvimento de colaboradores ou participantes em pesquisas. Ainda nos referindo às fontes documentais, conforme SáSilva, Almeida e Guindani (2009, p. 2):

\begin{abstract}
$\mathrm{O}$ uso de documentos em pesquisa deve ser apreciado e valorizado. A riqueza de informações que deles podemos extrair e resgatar justifica o seu uso em várias áreas das Ciências Humanas e Sociais porque possibilita ampliar o entendimento de objetos cuja compreensão necessita de contextualização histórica e sociocultural.
\end{abstract}

Assumimos a abordagem qualitativa de pesquisa, pois procuramos responder os objetivos de pesquisa a partir da interpretação dos documentos lidos à luz da literatura científica estudada. De acordo com Gil (2008, p. 177), "a manipulação qualitativa dos dados durante a análise é uma atividade eclética; não há uma única maneira de fazê-la. Embora se reconheça a importância de um arcabouço metodológico sólido, não se pode dispensar a criatividade do pesquisador". Já a abordagem quantitativa de pesquisa utilizamos apenas para mensurar os dados obtidos durante a coleta de dados.

Esta pesquisa traz análises de quatro dissertações. Observamos os seguintes critérios para seleção dos documentos: (a) produzida no Estado de Pernambuco ou Bahia; (b) apresentada no ano de 2018; (c) inserida no campo dos estudos linguísticos.

Não explicitamos os nomes das autoras nem mesmo as unidades em que foram produzidas as dissertações, assim evitamos alguma exposição indesejada. A fim de proporcionar maior compreensão dos estudos desenvolvidos pelas professoras, apresentamos sínteses dos referidos TCF.

Na primeira dissertação (DM1), por meio de um plano de trabalho, a autora buscou aprimorar as habilidades escritoras dos alunos envolvidos na pesquisa, focalizando o gênero artigo de opinião. Objetivou verificar se o ensino da escrita seria mais eficaz quando ocorre dentro de uma perspectiva interacional, contextualizada e processual. Com isso, a professora implementou o plano de trabalho planejado e, ao final, comparou a escrita dos alunos.

Na segunda dissertação (DM2), a autora buscou, por meio do que denominou oficinas de letramento, contribuir para o ensino da escrita a alunos surdos. A pesquisa foi realizada em uma sala de aula onde havia a presença de um aluno surdo e o projeto foi aplicado junto aos demais estudantes da turma, porém o foco foi a interação, considerando as reações do aluno com surdez diante das atividades propostas. A pesquisa não foi realizada na sala de aula da própria professora. Ela decidiu realizar a intervenção em uma escola com maior quantitativo de surdos, mesmo considerando a recorrente evasão escolar desse alunado.

Na terceira dissertação (DM3), a autora trata da mediação na revisão e reescrita de textos por parte de dois professores dos anos iniciais do Ensino Fundamental, mais especificamente nos $4^{\circ}$ e $5^{\circ}$ anos. Para analisar como essa mediação era empreendida, a autora se utilizou da entrevista, observação de aulas de LP e análise de textos discentes, que sofreram marcas interventivas. O objetivo geral da pesquisa foi investigar como aconteceram as práticas de revisão e reescrita e, assim, compreender que concepções de texto, língua e escrita tinham os professores, quais metodologias utilizavam e marcas interventivas, bem como que aspectos eram privilegiados na mediação.

A análise evidenciou que a escrita foi tomada como consequência ou produto. Os objetivos da escrita não eram amplos, os apontamentos no texto frisavam 
em sua maioria aspectos normativos da língua e apresentação de soluções aos problemas destacados. Não foi incentivada a reflexão discente sobre o próprio texto, mesmo quando foram reescritos, os aspectos gramaticais eram realçados. Assim, compreendeu-se que as etapas de reescrita e revisão devem ser melhor exploradas. A fim de contribuir com essa melhora, a autora desenvolveu três oficinas que versavam sobre a temática de gêneros textuais, avaliação dialógica e estratégias para revisão e reescrita.

$\mathrm{Na}$ quarta e última dissertação (DM4), a autora abordou mecanismos de coesão e coerência textuais e teve como objetivo a elaboração de uma proposta pedagógica que utilizasse como ferramenta a web pixton na produção de HQ. Esse trabalho foi identificado como pesquisa-ação, um grupo de professores de LP, dos anos iniciais e finais do Ensino Fundamental, obtive auxílio na abordagem de gêneros digitais. As oficinas pedagógicas empreendidas pela autora fizeram com que esse grupo de professores produzisse HQ por meio dessa ferramenta e pudesse refletir e discutir sobre o seu uso no ensino de coesão e coerência.

A autora analisou questionários produzidos no início e ao final da intervenção, as HQ produzidas, a avaliação dos professores sobre a própria produção e planos de aulas. Conclui-se que o trabalho contribuiu com a formação do grupo de professores visto que esses profissionais se tornaram mais aptos e inclinados a trabalhar com o gênero HQ, com ferramentas digitais e ampliaram concepções didáticas sobre o ensino de coesão e coerência.

Utilizamos uma Ficha Analítica elaborada por Silva (2019a, p. 57) e reproduzida no Anexo deste Artigo para auxiliar na leitura dos TCF, o que nos permitiu identificar um leque maior de informações e dar foco à leitura das dissertações.
Para auxiliar a análise das dissertações, utilizamos a noção de Estrutura Esquemática do Gênero (EEG), que possibilita a identificação e descrição das partes ou estágios componentes do gênero textual, no caso, dissertações ou TCF (EGGINS, 2004). Analisamos as seguintes partes textuais nos TCF: introdução; considerações teóricas; metodologia; análise dos dados; e considerações finais. Também atentamos para escolhas léxico-gramaticais realizadas por professoras na escrita das dissertações. À luz da Linguística Sistêmico-Funcional (LSF), em cada estágio do gênero, separamos as formas verbais, denominadas de processos, que estavam flexionadas na primeira pessoa do plural (nós), de alguma forma fazendo referência à autora da dissertação.

\section{A Linguística Sistêmico-Funcional} compreende a língua em contextos de uso. Segundo Eggins (2004 p.1-2), a LSF “é crescentemente reconhecida como uma estrutura descritiva e interpretativa muito útil para a compreensão de estratégias de criação de significado da língua"².

A LSF se caracteriza como sistêmica e funcional porque enxerga a língua como um sistema linguístico dinâmico e interligado. Esse sistema possibilita aos usuários uma série de escolhas possíveis para que se concretize uma comunicação ou interação significativa. Assim, também é funcional, pois a língua é utilizada em função de uma ação social, da produção de significados ou discursos em contextos específicos, daí a proposição de três metafunções da linguagem experiencial, interpessoal e textual (EGGINS, 2004).

Com o intuito de perceber os significados provocados pelas alunas-professoras, na escrita da dissertação, decidimos fazer uso da metafunção experiencial, responsável pela significação da experiência do usuário da língua no mundo exterior e no próprio interior, ou seja, nos pensamentos. Nossa microanálise linguística foca nos processos (formas

\footnotetext{
${ }^{2}$ A tradução foi feita livremente pelos autores desta pesquisa.
} 
verbais), uma categoria semântica que indica a experiência ligada aos participantes da construção gramatical das orações. Em outros termos, a metafunção focalizada se realiza no sistema de TRANSITIVIDADE.

A Gramática Sistêmico-Funcional elenca os seguintes processos que são passíveis de subcategorizações: verbal; mental; material; relacional; existencial; e comportamental. Interessanos as três primeiras classificações, pois foram mais recorrentes nos documentos analisados. Os processos verbais indicam comunicação, fala, discurso; os processos mentais contam das experiências internas, relacionadas à consciência, assim, percepção, intenção, emoção; já os processos materiais são os que apontam para o ato, fazer, produzir. A partir desses processos, identificamos diferentes tipos de participantes principais respectivamente - dizente, experienciador e ator (EGGINS, 2004; SILVA, 2014; 2019b).

\section{OBJETO DE INVESTIGAÇÃO NOS TCF}

O primeiro objetivo visa caracterizar o objeto de investigação que foi construído na dissertação pela aluna-professora. Assim, identificamos a relação desse objeto com as aulas de LP, bem como se deu o andamento da pesquisa e os métodos utilizados para alcançar os resultados.

A fim de exemplificar essas motivações, seguem alguns excertos selecionados a partir da ficha analítica. Nos exemplos, as palavras em maiúsculas identificam a seção da dissertação de onde foram selecionados os excertos, as palavras com somente letra inicial em maiúscula identificam o local da ficha analítica em que o excerto foi inserido na análise. Entre parênteses, registramos a autorrepresentação identificada professora, pesquisadora ou professora-pesquisadora. Essa última caracterização será focalizada, mais diretamente, na próxima seção deste artigo.
No Exemplo 1, a aluna-professora utilizou como objeto de investigação a escrita de textos a partir do gênero artigo de opinião. Visou a atender as recomendações dos Parâmetros Curriculares Nacionais (PCN), nos quais os gêneros textuais são propostos como objeto de ensino em aulas de LP, a fim de contribuir para a familiarização dos discentes com diferentes práticas sociais mediadas pela linguagem.

\section{Exemplo 1.}

DM1 - CONSIDERAÇÕES FINAIS - Dados investigados

Como a organização do ensino a partir dos gêneros textuais tem sido apontada como algo viável e fundamental para o aprimoramento das competências escritoras dos alunos pelos Parâmetros Curriculares Nacionais (1998), nossa pesquisa buscou atender a essa recomendação. Nossa intervenção girou em torno de um gênero textual, o Artigo de Opinião, muito embora outros estivessem presentes durante as atividades interventivas para ancorar as atividades propostas. Não foi aleatória a escolha de gêneros textuais como letra de música, quadrinhos, charge, vinheta, reportagens televisivas, etc, para dialogar com o nosso objeto de ensino e de estudo: o Artigo de Opinião. Esses gêneros foram escolhidos para demonstrar como a argumentação se manifesta nos diferentes gêneros textuais que circulam socialmente, sempre com o intuito de influenciar os interlocutores por meio de argumentos. (professora-pesquisadora)

O objeto de investigação em DM1 é o trabalho escolar sobre argumentação, mediado por atividades com diferentes gêneros textuais ("Esses gêneros foram escolhidos para demonstrar como a argumentação se manifesta nos diferentes gêneros textuais que circulam socialmente, sempre com o intuito de influenciar os interlocutores por meio de argumentos").

Conforme Exemplo 2, são utilizadas como objeto de investigação em DM2 oficinas de letramentos voltadas especificamente para alunos surdos, visando contribuir para o aprendizado do português escrito. As oficinas foram realizadas com toda a turma, mas com foco no aluno surdo.

\section{Exemplo 2. \\ DM2 - INTRODUÇÃO - Objetivos da investigação}

Diante dessas considerações, este trabalho teve como objetivo geral: compreender de que forma as oficinas de letramento podem contribuir para o aprendizado da Língua Portuguesa escrita por/pelo aluno(s) surdo(s) do Ensino 
Fundamental II que frequentam uma sala regular do $8^{\circ}$ ano, numa escola municipal em Itabuna. (professorapesquisadora)

A aluna-professora teve como objeto de investigação o aprendizado da escrita do português por alunos surdos. Utilizou-se de oficinas de letramento com atividades elaboradas por ela mesma. A relação desse objeto de investigação com as aulas de LP está no fato de a aluna-professora ter produzido atividades de leitura e escrita, garantindo a participação de todos os alunos. Até aqui, as professoras construíram objetos de investigação em respostas a demandas da sala de aula. Tais agências realçam o letramento do professor.

Quando os aspectos práticos não são devidamente explorados, dá-se lugar e autoridade à posição de pesquisador, deixando de lado a função do professor. Em outras palavras, quando a aluna-professora não escreve partindo da prática ou ignora esse aspecto como motivação da pesquisa, ela, de alguma forma, pode estar desvalorizando a escola básica e o papel desempenhado pelo professor. A validação do papel da professora é diretamente relacionada ao conhecimento das implicações políticas, assim a autoidentificação faz parte de um quadro de ações que projetam a valorização da professora na esfera política e acadêmica. $\mathrm{O}$ não posicionamento ou tratamento dos saberes da prática profissional, ainda que inconsciente, pode significar alguma fragilidade no processo de educação científica das professoras.

A terceira dissertação é um exemplo de que nem sempre essa relação entre a autoidentificação e o letramento científico são conscientes para a alunaprofessora. No Exemplo 3, a autora se identifica como professora e explicita a própria função, no entanto, no decorrer da introdução, observamos apenas justificativas teóricas para o empreendimento do trabalho.

Exemplo 3.

DM3 - INTRODUÇÃO - Pessoa Pronome da Escrita
Como professores de Língua Portuguesa, temos a complexa tarefa de mediar o desenvolvimento da capacidade textualdiscursiva dos estudantes, para que eles possam agir socialmente por meio de textos, sobretudo, em sua modalidade escrita. (professora)

Compreendemos que a autora entende necessário marcar o papel de professora, mas ainda assim não se aprofundou nas motivações práticas da pesquisa. Há uma ideia de que a teoria é marcadamente necessária para explicar a relevância do trabalho, o mesmo não ocorre com as questões práticas. Essa concepção se assemelha ao que é requerido na modalidade acadêmica de mestrado e tem então influenciado o modo de produção científica no MP (SILVA 2019c; SILVA e AIRES 2020; SILVA e FERREIRA, 2020).

Ainda podemos pontuar a preocupação da professora com o alunado em geral, visto que põe como relevante o desenvolvimento da capacidade textual-discursiva para que o aluno possa agir socialmente. Dessa forma, recordamo-nos do conceito de letramento do professor, em que práticas sociais envolvendo a escrita são viabilizadas pelo agente de letramento. A pesquisa visa contribuir com professoras no tocante à prática do uso da escrita em contextos amplos, como evidencia o Exemplo 4.

\section{Exemplo 4. \\ DM4 - CONSIDERAÇÕES FINAIS- Resultado}

Contudo, a partir da análise da avaliação das educadoras sobre as oficinas, acreditamos que agora estão mais conscientes sobre a importância de criar situações de escrita mais próximas dos contextos extraescolares de comunicação, bem como sobre o planejamento de atividades que favorecem o aprimoramento dos textos produzidos pelos aprendizes. (professora-pesquisadora)

A autora de D4 inicia a Introdução pontuando a necessidade de se trabalhar o texto em diversos contextos e coloca a utilização da HQ como uma alternativa para tal. $\mathrm{O}$ enfoque no gênero propicia $\mathrm{o}$ ensino de aspectos gramaticais em conformidade com o mesmo, tratando assim mais eficazmente a prática de análise linguística, a exemplo dos fenômenos da 
coesão e coerência, abordados pela autora ao longo do trabalho.

Todo esse caminho textual é amarrado e justificado por meio de pesquisas acadêmicas ou documentos oficiais que regulamentam o ensino brasileiro. Não é explicitado um fator da própria prática da autora que venha a fortalecer esse discurso. Em outra seção, a autora explicita o motivo para a escolha do gênero, conforme o Exemplo 5.

\section{Exemplo 5.}

DM4 - INTRODUÇÃO -Justificativa

Para empreender este processo de aprendizado coletivo, escolhemos o gênero história em quadrinho digital (Pixton). A escolha deveu se a uma experiência anterior de observação das aulas de alguns desses docentes (que foi realizada para título de trabalho de apresentação da disciplina de Alfabetização e Letramento do PROFLETRAS) durante as quais notamos que tanto nas turmas do ensino fundamental quanto nas turmas do ensino médio o uso de HQs era quase ausente no conteúdo das aulas ministradas, embora vários alunos estivessem lendo justamente HQs. (Pesquisadora)

A autora indica que foi nas aulas do MP, espaço acadêmico, que se originou a escolha pelo gênero. Não foram pontuadas as semelhanças dessa observação com a própria sala de aula da autora ou mesmo se as observações se deram em um ambiente já conhecido por ela. Porém é acrescentado: "Outro fator que nos impulsionou a escolha desse objeto foi as respostas dadas pelos docentes no questionário" (DM4). A partir desse questionário, a autora observou a dificuldade ou ausência de trabalho pedagógicos com textos diversos por parte das professoras das séries iniciais e finais do Ensino Fundamental, inclusive com os textos que circulam em ambiente digitais.

\section{AUTORREPRESENTAÇÃO NOS TCF}

A dissertação requerida no MP oportuniza a construção de autorrepresentações pela escrita. Segundo Bezerman (2015 p. 34-35), “os gêneros corporificam compreensões de situações, relações, posições, humores, estratégias, recursos apropriados, metas e muitos outros elementos que definem a atividade e formam meios de realização". Assim, a escrita presente nos TCF tem intrínseca a ela a compreensão consciente ou não da autora sobre as relações de poder. A escrita revela um posicionamento, uma vez que essa é envolvida por discursos. A palavra - ou a própria língua(gem) - não é neutra. As escolhas textuais são movidas por razões determinadas por um contexto específico.

O MP envolve atores de dois contextos específicos - universidades e escolas. Podemos compreender a aluna-professora como uma intersecção entre as instituições envolvidas, assim espera-se que a dissertação possa abarcar esses dois contextos e não dê espaço a discursos que venham diminuir a identidade profissional de professoras e pesquisadores. De acordo com Kleiman (2006, p.417),

Daí segue-se que as interações acadêmicas são centrais para o processo: o aluno se afilia a uma ou outra ideologia ou discurso profissional nessas interações, em particular àqueles discursos que tendem a oferecer respostas para as questões que afetam ou afetarão o cotidiano de suas práticas.

Dessa forma, a análise possibilita a visualização da interação escola básica e universidade pela aluna-professora com base na escrita do TCF. Na Tabela 1, temos o resultado da microanálise linguística de DM1. Trata-se de uma dissertação com EEG diferenciada, pois algumas partes constitutivas dessa estrutura foram fundidas em capítulos.

Tabela 1. Análise do processo da D1.

\begin{tabular}{|c|c|c|c|c|c|}
\hline $\begin{array}{l}\text { Processo } \\
\text { Estágio }\end{array}$ & $\mathbf{P}$ & Mat. & Men. & $\begin{array}{c}\text { Ver } \\
\text {. }\end{array}$ & Total \\
\hline Introdução & 01 & 00 & 00 & 00 & 00 \\
\hline $\begin{array}{c}\text { Considerações } \\
\text { Teóricas }\end{array}$ & 07 & 05 & 00 & 00 & 05 \\
\hline Metodologia & 13 & 10 & 06 & 09 & 25 \\
\hline $\begin{array}{c}\text { Análise } \\
\text { dos Dados }\end{array}$ & 59 & 96 & 24 & 19 & 139 \\
\hline $\begin{array}{c}\text { Considerações } \\
\text { Finais }\end{array}$ & 06 & 03 & 04 & 00 & 07 \\
\hline Total & 86 & 111 & 34 & 28 & 176 \\
\hline
\end{tabular}


$\mathrm{Na}$ Introdução, não identificamos a presença dos processos aqui focalizados na única página utilizada. Na Análise de Dados, ocorreu o maior número de páginas (59) e, consequentemente, houve mais processos, tendo os seguintes resultados: Material (96), Mental (24) e Verbal (19). O Material foi o que mais sobressaiu, isso pelo fato de a alunaprofessora registrar a realização das atividades com os alunos participantes.

Exemplo 6. DM1 - análise de dados.

Material
Buscamos oportunizar momentos de escrita dentro de
um viés colaborativo nos quais os estudantes interagiam,
oralmente, entre si, antes da escrita de textos. Estudos
apontam que o trabalho em colaboração é muito
produtivo para a aprendizagem dos alunos, sobretudo
em duplas ou em pequenos grupos. (professora-
pesquisadora)

\section{Mental}

Entendemos, porém, a avaliação como processo e não como simples produto, enquanto formação e não como medida, corroborando a ideia de que a intervenção didática não é sinônimo de correção de erros ortográficos e gramaticais. (professora)

\section{Verbal}

Como estratégia de leitura, pedimos que os alunos lessem a letra da referida canção e buscando identificar qual era a ideia principal que autor defendia no texto e quais foram os argumentos utilizados para sustentá-la. (professora)

No Exemplo 6, retirado da Análise de Dados, há ocorrência do processo Material (buscamos), em que a professora-pesquisadora se utiliza da colaboração oral entre os alunos para depois escrever o texto solicitado. No segundo excerto, temos o processo Mental (entendemos), a aluna-professora explicita compreender a avaliação como um processo importante. Também complementa a respeito da intervenção docente não se restringir simplesmente às correções ortográficas e gramaticais dos alunos. No último excerto do Exemplo 6, há o processo Verbal (pedimos), em que a aluna-professora pede que os alunos façam a leitura da música buscando as ideias principais, tendo como foco os argumentos utilizados pelo autor. Encontramos as seguintes autorrepresentações: professora, pesquisadora e professora-pesquisadora.

Em alguns casos a própria aluna-professora se autorrepresenta como professora-pesquisadora, como vemos em DM1: "Para cada oficina foram pensadas atividades e estratégias para atingir os objetivos propostos pela professora-pesquisadora". Além de fazer a autorrepresentação, a aluna-professora também deixa explícito que todas as atividades e estratégias foram planejados por ela visando responder os objetivos da pesquisa.

Na Tabela 2, observamos que, em DM2, nas Considerações finais, ocorreu o menor número de páginas (04) e também a menor quantidade de processos: Material (12), Mental (05) e Verbal (01). Em Análise de Dados, houve o maior número de páginas (35) e os seguintes processos: Material (75), Mental (33) e Verbal (15). A ocorrência do processo Material foi alta porque representa o relato da professora diante do trabalho realizado com os alunos, pois a mesma elaborou e aplicou as atividades em sala de aula.

Tabela 2. Análise do processo DM2.

\begin{tabular}{|c|c|c|c|c|c|}
\hline $\begin{array}{l}\text { Processo } \\
\text { Estágio }\end{array}$ & $\mathbf{P}$ & Mat. & Men. & Ver. & Total \\
\hline Introdução & 08 & 15 & 06 & 03 & 24 \\
\hline $\begin{array}{c}\text { Considerações } \\
\text { teóricas }\end{array}$ & 25 & 39 & 16 & 10 & 65 \\
\hline Metodologia & 13 & 29 & 09 & 03 & 41 \\
\hline $\begin{array}{c}\text { Análise } \\
\text { dos dados }\end{array}$ & 35 & 75 & 33 & 15 & 123 \\
\hline $\begin{array}{c}\text { Considerações } \\
\text { finais }\end{array}$ & 04 & 12 & 05 & 01 & 18 \\
\hline Total & 85 & 170 & 69 & 32 & 271 \\
\hline
\end{tabular}

O Exemplo 7 foi retirado das Considerações teóricas. No primeiro excerto, temos o processo Material (Iniciamos) em que a aluna-professora se utiliza do dizer de André (2016) para iniciar os argumentos a respeito do professor em sala de aula e a 
oportunidade de ter uma reflexão crítica sobre a própria prática. No segundo excerto, há o processo Mental (acreditamos), a aluna-professora, autorrepresentada como pesquisadora, acredita que a representação da pessoa surda deve ser feita com a palavra diferença e não com deficiência. Dessa maneira, haverá a possibilidade de que as práticas pedagógicas sejam redimensionadas para os alunos surdos. No último excerto, com o uso do processo Verbal (declaramos), a aluna-professora, autorrepresentada como professora-pesquisadora, declara, assim como fez em outra parte da dissertação, que, no Brasil, existem duas propostas diferentes sobre a educação de alunos surdos.

Exemplo 7. DM2 - considerações teóricas.

\begin{tabular}{l} 
Material \\
Iniciamos assim com o argumento de André (2016), \\
que afirma que para garantir uma aprendizagem \\
significativa dos alunos, é necessário que ajam (sic) \\
processos formativos nos quais os docentes tenham a \\
oportunidade de refletir criticamente sobre a sua \\
prática, nas palavras da autora, refletir criticamente \\
significa se debruçar sobre o próprio trabalho para \\
poder entender aquilo que está sendo feito, ponderar o \\
que é bom, sobre os acertos e o que é preciso mudar \\
para obter melhores resultados. \\
pesquisadora) \\
\hline Mental professora- \\
Conforme foi indicado no capítulo I, acreditamos que \\
essa primeira representação da surdez, a deficiência \\
[grifo nosso], precisa ser substituída pela ideia de \\
diferença [grifo nosso], essa "nova" perspectiva \\
possibilitará que o professor de Lp identifique formas \\
possíveis de redimensionar a sua prática pedagógica de \\
maneira que contemple a especificidade linguística \\
dos estudantes surdos, atuando no sentido de pensar e \\
criar estratégias para alguém que apreende o mundo a \\
partir do que vê e não do que ouve, será um movimento \\
de capturar esse estudante para as aprendizagens que \\
serão significadas pela visão. (pesquisadora)
\end{tabular}

\footnotetext{
Verbal

Conforme declaramos anteriormente, atualmente permanecem no Brasil duas propostas diferenciadas, alguns pesquisadores sustentam que os surdos devem estudar em escolas regulares, atendendo a política de inclusão do governo federal (MANTOAN, 2005; DAMÁZIO, 2007), e outros apontam para outra direção, e defendem que a educação desses sujeitos deverá estar atrelada a sua língua, cultura e história, elementos indispensáveis na formatação do currículo e dos processos pedagógicos dentro da escola bilingue. (QUADROS, 1997; SKLIAR, 1999; FERNANDES, 2009). (professora-pesquisadora)
}

A DM3 também apresenta o uso das autorrepresentações como professora e pesquisadora. A autora se identifica como professora ("Como professores de Língua Portuguesa, temos a complexa tarefa de mediar o desenvolvimento da capacidade textual-discursiva dos estudantes"), no entanto, em outro momento, a autora se caracteriza como pesquisadora e se distancia da função de professora ("Geralmente, nossos interlocutores são outros pesquisadores, estudantes universitários, professores da educação básica.”). Nesse excerto entre parênteses, reproduzido das Considerações Teóricas, a autora se coloca como pesquisadora. Poderia ter declarado exercer as duas funções, no entanto a estratégia textual utilizada foi a de especificar uma como beneficiária da outra. O exemplo aponta para a modulação na autorrepresentação, já que em alguns momentos a autora indica o ambiente da escola básica, no entanto na maior parte privilegia o espaço acadêmico.

$\mathrm{Na}$ Tabela 3, as considerações teóricas é um estágio que apresenta um quantitativo expressivo de páginas (56), tendência observada na pesquisa.

Tabela 3. Análise do processo da DM3.

\begin{tabular}{|c|c|c|c|c|c|}
\hline $\begin{array}{c}\text { Processo } \\
\text { Estágio }\end{array}$ & $\mathbf{P}$ & Mat & Men. & $\begin{array}{c}\text { Ver } \\
.\end{array}$ & Total \\
\hline Introdução & 06 & 05 & 06 & 03 & 14 \\
\hline $\begin{array}{c}\text { Considerações } \\
\text { teóricas }\end{array}$ & 56 & 12 & 47 & 28 & 89 \\
\hline Metodologia & 08 & 18 & 20 & 08 & 46 \\
\hline $\begin{array}{c}\text { Análise } \\
\text { dos dados }\end{array}$ & 60 & 11 & 98 & 27 & 136 \\
\hline $\begin{array}{l}\text { Considerações } \\
\text { finais }\end{array}$ & 04 & 0 & 25 & 01 & 26 \\
\hline Total & 134 & 51 & 197 & 63 & 311 \\
\hline
\end{tabular}

O estágio mais volumoso é o de análise de dados (60), ainda que demonstre algum equilíbrio com o espaço reservado às considerações teóricas. Em DM3, o uso mais recorrente de processo é o Mental (197) e está alinhado às teorias de base utilizadas pela autora e não necessariamente a alguma reflexão sobre 
a prática ("No exemplo abaixo, extraído da pesquisa de Ruiz (2001), podemos observar"; “Compartilhamos a compreensão de Silva e Suassuna (2017)”). Esse processo é utilizado ainda, majoritariamente, para examinar os dados da pesquisa ("Esses problemas estruturais e discursivos que verificamos no texto analisado"; "podemos notar, por se tratar de um mero exercício de cópia”). Tal uso é exemplificado pela tabela já que é no estágio de Considerações Teórica (47) e Análise dos Dados (98) que os processos ganham mais vazão e assim atuam se adequando às necessidades desses estágios como mostram os excertos.

Os processos Materiais aparecem expressivamente para tratar da coleta de dados ("Em nossa pesquisa, utilizamos esses três instrumentos") e relacionados a ações atreladas a teorias de base ('Marcuschi (2008) afirma que, quando ensinamos algo"; "Apresentamos, brevemente, diferentes perspectivas teóricas"). Esses usos ilustram os números mais relevantes nos estágios de considerações teóricas (12), metodologia (18) e análise de dados (11).

Quanto aos processos Verbais, o uso está associado ao diálogo da autora com as teorias de referência ("cujos pressupostos discutimos anteriormente"; "podemos citar Roman Jakobson (1896-1982), do Círculo Linguístico de Praga") e estabelecimento de comunicação entre os atores da pesquisa ("realizamos conversas informais"; "Quando perguntamos à educadora"). Dessa forma, compactua com os números apresentados pela tabela nos estágios de Considerações Teóricas (28) e Análise de Dados (27).

Assim, percebemos que a cultura acadêmica, ou mesmo o modus operandi da academia influencia a escrita da dissertação. O modelo utilizado pelo MP para a produção do TCF é um fator responsável por esse distanciamento do papel de professora. Segundo apresenta Silva (2019c, p. 278), “A esse modelo podese atribuir a responsabilidade pelo silenciamento ou alinhamento das professoras diante das teorias acadêmicas, restando ao profissional do magistério copiar, reproduzir ou, simplesmente, parafrasear os conhecimentos produzidos na/pela universidade".

Esse modelo pode ser revisado para que as vozes representantes da comunidade escolar sejam mais audíveis. Em DM3, por exemplo, ainda que a análise de dados seja excepcionalmente maior que outros estágios, o uso dos processos permanece como nas outras dissertações, o que nos indica a pouca flexibilidade do modelo utilizado. Em DM4, essa falta de flexibilidade textual se faz ainda mais presente. A dissertação apresenta poucas autorrepresentações, sendo essas apenas do papel de pesquisadora.

Exemplo 8. DM4 - considerações finais.

uma vez que o conhecimento foi construído pelo grupo e os resultados da intervenção foram frutos da parceria participantes/pesquisadora.

O Exemplo 8 aponta para a autorrepresentação como pesquisadora. Assim, mais uma vez, fica perceptível a influência da cultura academia, já que a autora sentiu necessidade ou a possibilidade de se apresentar como pesquisadora, no entanto o mesmo não ocorre com a função de professora. Também podemos notar essa influência no uso de processos.

Tabela 4. Análise do Processo da DM4.

\begin{tabular}{cccccc}
\hline $\begin{array}{c}\text { Processo } \\
\text { Estágio }\end{array}$ & P & Mat. & Men. & Ver & Total \\
\hline Introdução & 07 & 06 & 15 & 13 & 34 \\
\hline $\begin{array}{c}\text { Considerações } \\
\text { teóricas }\end{array}$ & 73 & 30 & 65 & 35 & 131 \\
\hline $\begin{array}{c}\text { Metodologia } \\
\text { Análise }\end{array}$ & 34 & 54 & 35 & 45 & 134 \\
\hline $\begin{array}{c}\text { dos dados } \\
\text { Considerações } \\
\text { finais }\end{array}$ & 05 & 03 & 15 & 10 & 28 \\
\hline Total & $\mathbf{1 5 1}$ & 113 & 198 & 133 & 444 \\
\hline & Fonte: Autoria Própria & & \\
\hline & & & & & \\
\hline
\end{tabular}


Na Tabela 4, o estágio de considerações teóricas foi o mais extenso (73), outro dado expressivo foi a utilização dos processos Mentais (198). Esse tipo de processo foi usado para manifestar reflexão sobre a teoria de base ("Uma vez que entendemos que as teorias"; "escolhemos aqui para tratar com o corpus desse estudo esta abordagem") e para diagnóstico dos dados colhidos ("Outra questão que podemos notar neste texto"; "observamos no trecho do texto analítico da dupla C"). Esse processo foi mais empregado em considerações teóricas (66) e análise de dados (67).

Os processos Materiais se apresentam acentuados na Metodologia (54) e remetem a atividades de coleta de dados ("apresentamos a proposta de formação docente"; "realizamos três oficinas pedagógicas") ou complementaram a reflexão sobre a teoria ("por isso é que ao construirmos um texto, buscamos utilizar mecanismo coesivos que suscitem relações dentro do texto que favoreçam a continuidade textual"; "Neste trabalho recortamos do quadro 2 para fomentar a discussão da análise da coesão e da coerência das HQs digitais (Pixton) as relações textuais (reiteração e conexão)"). Tais usos explicam os quantitativos 20 e 30 apresentados na tabela, respectivamente, já que correspondem ao que requer o estágio.

Os processos Verbais são utilizados mais enfaticamente em Considerações Teóricas (35), Metodologia (45) e Análise de Dados (30). São empregados para enfatizar conceitos ou conclusões de base teórica ("nos deteremos a discutir a seguir sobre gramática de uso linguístico "; "discorremos, a seguir, um pouco sobre as manifestações apresentadas por Franco"), expor atividades referentes à realização da pesquisa ("descreveremos como dividimos as etapas da coleta de dados "; " "propusemos o trabalho em dupla ") e para fazer relações entre a análise e a teoria de base ("discorremos a respeito das análises dos mecanismos de coesão "; "Relação sobre a qual discutimos a seguir").
Ao analisarmos o uso dos processos nas quatros dissertações, observamos a influência do modelo acadêmico sobre a escrita no MP, uma vez que os processos foram usados majoritariamente condicionados à teoria. Ainda se pode destacar a predileção pelo uso do papel de pesquisadora enquanto o de professora é minimizado.

\section{CONSIDERAÇÕES FINAIS}

O desenvolvimento da educação científica é gradual. Ao analisarmos indiretamente a apropriação dessa prática no ProfLetras, a partir do exame de algumas dissertações, percebemos a utilização de saberes científicos pelas alunas-professoras. Em certa medida, ao produzirem o TCF, elas fazem pesquisa sobre o próprio ambiente de trabalho, o que contribui para a formação individual. Esperamos que, ao concluírem o MP, as professoras continuem pesquisando na e sobre sala de aula.

Com pouca experiência em pesquisa, as alunas-professoras são propensas a assumir procedimentos consolidados pela tradição acadêmica, tendo maior resistência para focalizar demandas do local de trabalho, as quais, ironicamente, motivam o retorno das profissionais às universidades. O MP precisa contribuir para a conscientização e a criticidade das alunas-professoras diante de saberes especializados e práticas investigativas, garantindo $o$ uso desses elementos conforme a realidade de cada escola.

De acordo com Moita Lopes e Cavalcanti (1991, p. 133), "No contexto educacional brasileiro, a sala de aula de línguas tem sido predominantemente um local de ensino e muito raramente um local de pesquisa". Esse excerto foi selecionado de uma publicação da última década do século passado, no âmbito da LA. Percebemos que, na segunda década do Século XXI, o desenvolvimento da pesquisa na sala de aula ainda é um desafio. 
A escolha da dissertação como produto final do curso precisa ser constantemente repensada ou problematizada a partir de autoavaliações do programa ou de pesquisas científicas. A incidência dos processos focalizados se relaciona diretamente aos estágios utilizados no modelo acadêmico de dissertação e tende a privilegiar aspectos teóricos. Silva (2019c, p. 278279) alertou que a persistência desse modelo pode resultar numa ameaça à "autonomia das professoras que retornam à universidade numa posição privilegiada do ponto de vista da experiência profissional acumulada."

Nesse sentido, registramos nossa sugestão de aprimoramento do trabalho final utilizado no MP. Fazse necessária uma EEG que auxilie a utilização de processos responsáveis pela reflexão sobre as próprias aulas de LP, possibilitando maior eficiência no compartilhamento de experiências e na reflexão sobre a complexidade do espaço escolar. Em síntese, a pesquisa precisa desencadear um olhar de estranhamento das professoras sobre a escola, ainda que se caracterize como um local extremamente familiar a elas. A investigação científica também surpreende, produz resultados inesperados e, por vezes, nem sempre agradáveis!

\section{AGRADECIMENTO}

Agradecemos ao Conselho Nacional de Desenvolvimento Científico e Tecnológico (CNPq) pela Bolsa de Produtividade em Pesquisa $\left(\mathrm{CNPq} n^{\circ}\right.$ 305094/2016-5305094/2016-5) e pela Bolsa de Iniciação Científica, que financiaram a realização da pesquisa resultante neste artigo científico.

Todos os autores declararam não haver qualquer potencial conflito de interesses referente a este artigo.

\section{REFERÊNCIAS}

BAZERMAN, C. Retórica da ação letrada. São Paulo: Parábola Editorial, 2015. p. 200
EGGINS, S. An introduction to Systemic Functional Linguistic. 2. ed. London: Continuum, 2004.

GIL, A. C. Métodos e técnicas de pesquisa social. $6^{\mathrm{a}}$ Ed. São Paulo: Atlas, 2008.

KLEIMAN, A. B. Professores e agentes de letramento: identidade e posicionamento social. Filologia e Linguística Portuguesa. São Paulo: USP, v. 8, p. 409424, 2006.

KLEIMAN, A. B. Letramento na contemporaneidade. Bakhtiniana. São Paulo: PUCSP, p. 72-91, 2014.

LEA, Mary R.; STREET, Brian V. O modelo de "letramentos acadêmicos": teoria e aplicações Tradução: KOMESU, Fabiana; FISCHER, Adriana. Filologia e Linguística Portuguesa. São Paulo: USP, v. 16, n. 2, p. 477-493, 2014.

MOITA LOPES, L. P.; CAVALCANTI, M. Implementação de pesquisa na sala de aula de línguas no contexto brasileiro. Trabalhos de Linguística Aplicada. Campinas: Unicamp, v. 17, n. s/n, p. 133$141,1991$.

MOITA LOPES, L. P.; FABRÍCIO, B. F. Por uma 'proximidade crítica' nos estudos em Linguística Aplicada. Calidoscópio. São Leopoldo: Unisinos, v. 17, n. 4, p.711-723, 2019.

PENNYCOOK, A. Critical Applied Linguistics: a critical introduction. New York: Routledge, 2001.

Regimento Interno do ProfLetras - Anexo da Resolução no 043/2012-CONSEPE, de 15 de maio de 2012. Disponível em: - Resolução no 043/2012. Disponível em: http://www.profletras.ufrn.br/Documentos/10896319 1/ regimento\#.Wqbg7OjwbIU. Acesso em: 16 ago. 2020 .

SÁ-SILVA, J. R.; ALMEIDA, C. D.; GUINDANI, J. F. Pesquisa documental: pistas teóricas e metodológicas. Revista Brasileira de História \& Ciências Sociais. v. 1, n. 1, 2009, p. 1-15

SILVA, W. R. Reflexão pela escrita no estágio supervisionado da licenciatura: pesquisa em Linguística Aplicada. Campinas: Pontes Editores, 2014.

Construção de práticas de pesquisa no Mestrado Profissional em Letras. In: SILVA, W. R.; BEDRAN, P. F.; BARBOSA, S. A. (Org.). Formação de professores de língua na pós-graduação. Campinas: Pontes, 2019a. p. 25-57. 
Prática científica na escrita da professora. Linguagem em (Dis)curso. Tubarão: Unisul, v. 19, n. 2, p. 273-292, 2019 b.

. (Org.). Contribuições sociais da Linguística Aplicada: uma homenagem a Inês Signorini. Campinas: Pontes, 2021.

; CORDEIRO, M. R.; FARAH, B. F.; MORAES, C. W. R.; SOUSA, D. L.; SILVA, L. L. S.; MENDES, V. C. B. B. Ciência nas licenciaturas?
Linguagem: Estudos e Pesquisas. Catalão: UFG, vol. 22, n. 1, p. 83-108, 2018.

; AIRES, N. Educação científica de professoras em mestrado profissional. The Especialist. São Paulo: PUC, v.41, n. 2, p. 1-21,2020.

; FERREIRA, R. Educação cientifica de professoras revelada em dissertações de mestrado. Humanidades \& Inovações. Palmas: Unitins, v.7, n. 8, p.189-205, 2020.

Anexo

Ficha Analítica (SILVA, 2019a, p. 57)

\begin{tabular}{|c|c|c|c|}
\hline TITULO DA DISSERTAÇÄO & & & \\
\hline ORIENTADOR & & & \\
\hline UNIDADE ACADEMICA & & & \\
\hline ITENS DE REFE & 2ENCIA & FXFMPIFICACÃO & ANÁUISF \\
\hline SUBITENS DE REF & ERENCIA & САЕIVIPLIVICAÇAU & AINALISL \\
\hline Pessoa pronome de escrita da & dissertação & & \\
\hline Justificativa para pesquisa & & & \\
\hline Local da pesquisa & & & \\
\hline Dados investigados & & & \\
\hline Abordagem teórica & & & \\
\hline & Disciplinar & & \\
\hline & Interdisciplinar & & \\
\hline Atitude investigativa & Transdisciplinar & & \\
\hline & Multidisciplinar & & \\
\hline & Indisciplinar & & \\
\hline & Qualitativa & & \\
\hline Abordagem investigativa & Quantitativa & & \\
\hline & Documental & & \\
\hline & Pesquisa-Ação & & \\
\hline Tipo de pesquisa & Participante & & \\
\hline & Estudo de Caso & & \\
\hline & Etnografia & & \\
\hline & Outro & & \\
\hline Forma de elaboração do & Perguntas & & \\
\hline problema de pesquisa & Objetivos & & \\
\hline & Hipóteses & & \\
\hline & Outro & & \\
\hline Tematização de aspectos ético & & & \\
\hline Resultados & & & \\
\hline Encaminhamentos & & & \\
\hline Produto gerado & & & \\
\hline Observação & & & \\
\hline
\end{tabular}

